\title{
CELL SIZE CHANGES IN THE LATERAL GENICULATE NUCLEI OF NORMAL AND MONOCULARLY DEPRIVED CATS TREATED WITH 6-HYDROXYDOPAMINE AND/OR NOREPINEPHRINE ${ }^{1}$
}

\author{
PETER F. HITCHCOCK AND T. L. HICKEY ${ }^{2}$ \\ School of Optometry/The Medical Center, University of Alabama in Birmingham, Birmingham, Alabama 35294
}

Received December 22, 1980; Revised January 11, 1982; Accepted January 14, 1982

\begin{abstract}
Given the proposed role of catecholamines in controlling cortical plasticity in the cat (Kasamatsu, T., J. D. Pettigrew, and M. Ary (1979) J. Comp. Neurol. 185: 163-182), we were interested in whether evidence of such control also could be found in the dorsal lateral geniculate nucleus. We undertook geniculate cell size measurements in 26 normal or monocularly deprived cats, 23 of which had been used in cortical recording studies concerned with catecholamine-induced plasticity. For animals grouped according to experimental treatments, the results can be summarized as follows: (1) in visually normal animals, neither intraventricular injections of 6-hydroxydopamine (6-OHDA) nor local perfusions of norepinephrine (NE) cause changes in geniculate cell size. (2) In otherwise untreated kittens, 1 week of monocular deprivation begun in the 6th week of life results in quite obvious changes in geniculate cell size. (3) Intraventricular injections of 6-OHDA do not appear to prevent deprivation-induced changes in geniculate cell size. (4) Older NE-treated kittens and adult cats that are monocularly deprived for a brief period either late in the critical period or after the critical period has ended do not show deprivation-induced changes in geniculate cell size in either hemisphere. (5) In younger kittens which had been first injected with 6-OHDA intraventricularly and then monocularly deprived for a brief period early in the critical period, there is no evidence to suggest that a local perfusion of $\mathrm{NE}$ enhances deprivation-induced changes in geniculate cell size.
\end{abstract}

The role of catecholamines in the preservation of cortical plasticity as it relates to visual form deprivation has been demonstrated by Kasamatsu and Pettigrew (1976, 1979). When brain catecholamines are depleted in kittens as a result of intraventricular injections of 6-hydroxydopamine (6-OHDA), cortical cells become insensitive to monocular deprivation. The cortical plasticity lost as a result of intraventricular injections of 6-OHDA can be restored, however, if such cortex is perfused directly with exogenous norepinephrine (NE) (Pettigrew and Kasamatsu, 1978; Kasamatsu et al., 1979). For example, when

\footnotetext{
' This work was supported by National Institutes of Health Grants EY01338 (T. L. H.), EY03039 (CORE), and RR05807 (Biomedical Research Support Grant). The animals provided by Drs. Kasamatsu, Pettigrew, and Ary were supported by National Institutes of Health Grants MH25852 and EY1909, the Whitehall Foundation (J. D. Pettigrew), and National Science Foundation Grant B.N.S. 77-19433 and National Institutes of Health Grant EY03409 (T. Kasamatsu). We thank Ken Hamrick, Tom Wilkinson, Barbara Ciampa, Rick Davis, and Caroline Dunn for their excellent technical and secretarial assistance. We also thank Drs. David Sparks and Clyde Oyster for their helpful comments on an earlier version of the manuscript.

${ }^{2}$ To whom correspondence should be addressed.
}

NE is perfused locally into one cortical hemisphere of a 6-OHDA-treated cat, deprivation-induced changes in cortical cell physiology occur only in the NE-treated hemisphere and, even then, only in the region of the hemisphere receiving effective concentrations of NE. In kittens, such deprivation-induced changes in cortical physiology include the loss of binocularity and a shift in ocular dominance away from the deprived eye. In older animals, normally considered to be past the "critical period" of development (Hubel and Wiesel, 1970), local perfusion of NE still restores some plasticity as evidenced by the fact that even a brief period of monocular deprivation begun at this time results in the loss of cortical cell binocularity. The situation in the older animals differs from that seen in kittens, however. In the older animals, the loss of binocularity is not accompanied by the usual shift in ocular dominance away from the deprived eye but, rather, results in U-shaped ocular dominance distributions, with many cells still being controlled by the deprived eye.

In light of these changes in cortical cell physiology following a brief monocular deprivation, we were interested in whether structural changes occurred in the lat- 
eral geniculate nuclei (LGN) of these same animals. Specifically, we were interested in (1) whether intraventricular injections of 6-OHDA or local perfusions of NE had any effect on geniculate cell size in visually normal animals, (2) whether intraventricular injections of 6OHDA would prevent deprivation-induced changes in geniculate cell size, and (3) whether the restoration of cortical plasticity resulting from local perfusions of $\mathrm{NE}$ is reflected in changes in geniculate cell size.

\section{Materials and Methods}

The lateral geniculate nuclei from 26 cats were studied. Twenty-three of these cats had been used in electrophysiological investigations of catecholamine-induced cortical plasticity (Kasamatsu and Pettigrew, 1979; Kasamatsu et al., 1979), allowing direct comparisons between the physiological and anatomical results. To facilitate such comparisons, the same identification numbers used in the physiological studies also are used here. Three of the animals were used only for geniculate cell size measurements and were not included in the prior recording studies.

Blocks of tissue containing both lateral geniculate nuclei, coded to conceal animal identification, were kindly provided by Dr. Takuji Kasamatsu (Division of Biology, California Institute of Technology, Pasadena, CA). Each block was processed routinely for celloidin embedding. Coronal sections were cut at $40 \mu \mathrm{m}$ and stained with cresyl violet. In each nucleus, the cross-sectional areas of 200 cells were determined (see Hickey et al., 1977, for details of the cell measurement procedures). Cells were measured in the binocular segment of lamina $A$ and lamina $A_{1}$ at a rostrocaudal level corresponding to a region just anterior to coronal plane 5 (anterior 6.5; Sanderson, 1971). Coronal sections through this part of the nucleus represent a region in the visual field $2^{\circ}$ to $5^{\circ}$ below the horizontal meridian. Likewise, the mediolateral location of the cells sampled in lamina $A$ and lamina $A_{1}$ (8.5 to $9 \mathrm{~mm}$ lateral) corresponds to a region in the visual field $2^{\circ}$ to $5^{\circ}$ off of the vertical meridian (Sanderson, 1971). Based on a conservative estimate of $5 \mathrm{~mm}$ for the spread of locally perfused NE (see Kasamatsu et al., 1979 , 1981, for details concerning the evidence that supports such an estimate) and on the stereotaxic coordinates given by these authors coupled with the cortical maps provided by Tusa et al. (1978), we are confident that the geniculate cells measured projected to regions of the visual cortex receiving effective concentrations of NE. When 6-OHDA is injected into the ventricle, it is assumed that geniculate, as well as cortical, cells in both hemispheres are exposed to this chemical agent (Kasamatsu and Pettigrew, 1979).

Descriptions of the experimental conditions are provided as the findings for each group of animals are presented and in summary form in Figure 1. Describing the various experimental treatments in this way makes it easier to relate changes in geniculate cell size to the previously reported changes in cortical cell physiology (Kasamatsu and Pettigrew, 1979; Kasamatsu et al., 1979). (Note: for animals used in the electrophysiological experiments, cortical recordings were begun immediately following the terminations of the experimental treatments

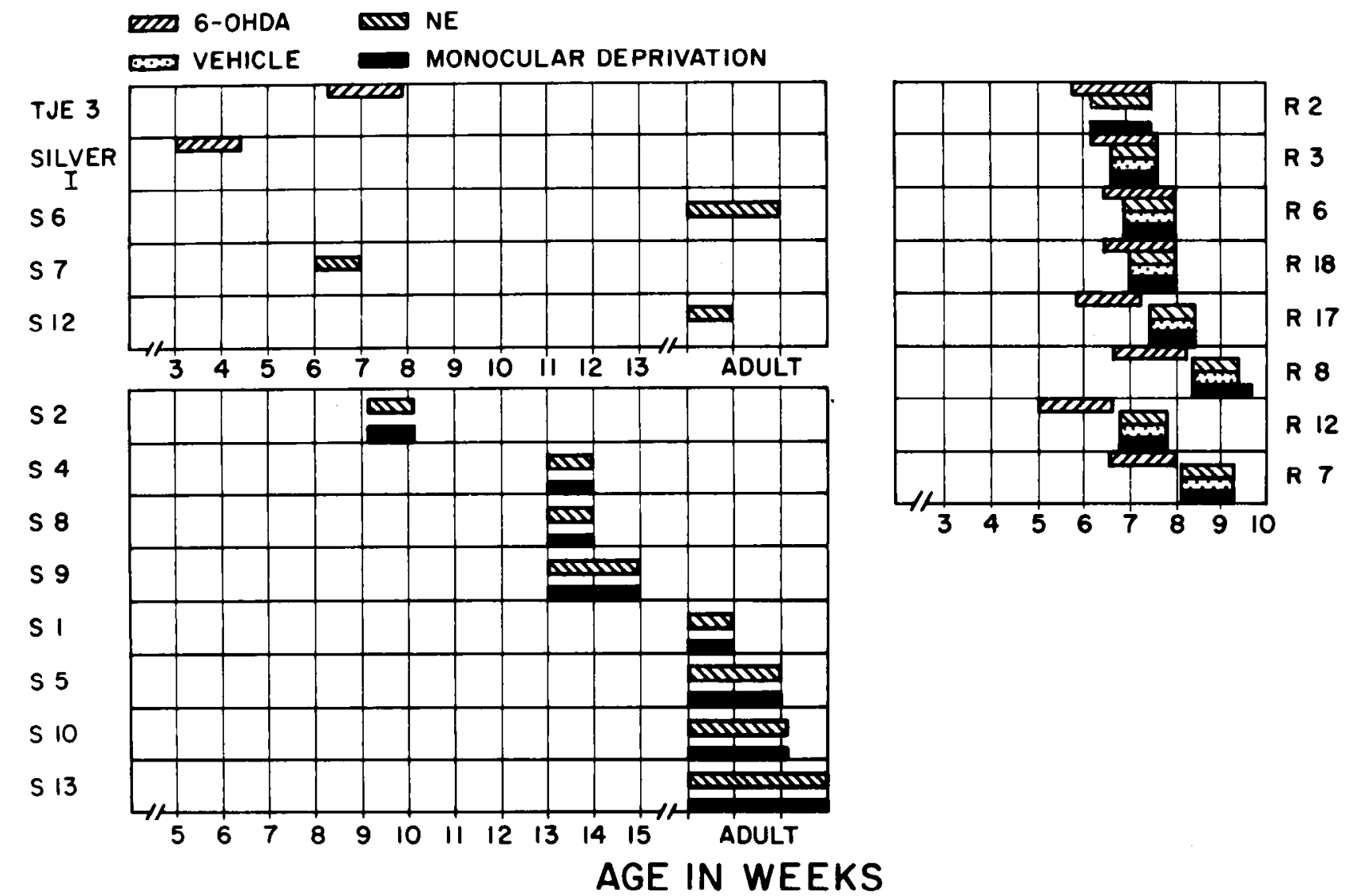

Figure 1. Chart showing the ages and experimental treatments for the animals used in this study. Each block containing 3 or more animals corresponds to an experimental group (also see Table I). 
outlined in Fig. 1. Each of these animals was sacrificed at the end of the recording session). To facilitate comparisons between the anatomical and physiological results, a brief summary of the main physiological findings for each group of animals is presented. Some aspects of the experimental treatments were held constant, however, and can be described once for all animals. All lid suturing was done for the right eye all intraventricular injections of 6OHDA were made in the right lateral ventricle, and all local perfusions of $\mathrm{NE}$ were made in the left hemisphere. In all but 1 (R2) of the catecholamine-treated animals that received both 6-OHDA and NE, a local perfusion of vehicle solution ( $0.4 \%$ ascorbate in normal saline, $\mathrm{pH} 3$ ) was made in the right, control hemisphere at a point corresponding to the site of the NE perfusion in the left, experimental hemisphere. Three of the animals (TB, TC, and TD) did not receive any experimental (drug) treatments but did receive 1 week of monocular deprivation beginning in the 6th week of postnatal life and were sacrificed at the beginning of their 7 th week of life. These animals provide previously unavailable data on the deprivation-induced changes in geniculate cell size that occur following only 1 week of lid suture. Other information about the animals and experimental treatments can be found in Figure 1 (also see Kasamatsu et al., 1979). Since the 3 monocularly deprived kittens just described did not undergo any additional experimental treatments, we have not included them in Figure 1.

The average cross-sectional area of cat geniculate cells can vary tremendously even in similarly aged animals (for example, see Hickey, 1980). Such variability makes comparisons between individual animals risky at best. A

TABLE I

Geniculate cell cross-sectional area in normal and visually deprived cats

\begin{tabular}{|c|c|c|c|c|}
\hline \multirow{3}{*}{ Cat } & \multicolumn{4}{|c|}{ Normally Reared Animals } \\
\hline & \multicolumn{2}{|c|}{ Left } & \multicolumn{2}{|c|}{ Right } \\
\hline & A & $\mathbf{A}_{1}$ & A & $A_{1}$ \\
\hline & \multicolumn{4}{|c|}{$\mu m^{2}$} \\
\hline TJE3 & 185.1 & 205.3 & 182.8 & 206.5 \\
\hline Silver I & 190.3 & 217.2 & 186.5 & 177.8 \\
\hline Average & 187.7 & 211.2 & 184.5 & 192.2 \\
\hline S6 & 209.2 & 204.6 & 235.1 & 242.6 \\
\hline S7 & 238.1 & 285.7 & 229.2 & 267.4 \\
\hline $\mathrm{S} 12$ & 190.6 & 219.8 & 195.1 & 236.6 \\
\hline Average & 212.6 & 236.7 & 219.8 & 248.9 \\
\hline \multirow[t]{2}{*}{ Average $\pm \mathrm{SE}$} & $202.6 \pm 9.8$ & $226.5 \pm 15.1$ & $205.7 \pm 11.0$ & $226.2 \pm 15.5$ \\
\hline & \multicolumn{4}{|c|}{ Visually Deprived Animals } \\
\hline \multirow[t]{3}{*}{ Cat } & \multicolumn{2}{|c|}{ Deprived } & \multicolumn{2}{|c|}{ Nondeprived } \\
\hline & A Left & A 1 Right & A Kight & $A_{1}$ Left \\
\hline & \multicolumn{4}{|c|}{$\mu m^{2}$} \\
\hline $\mathrm{TB}$ & 183.7 & 201.1 & 226.1 & 227.1 \\
\hline TC & 217.8 & 227.0 & 251.2 & 235.6 \\
\hline $\mathrm{TD}$ & 198.5 & 224.1 & 222.2 & 262.0 \\
\hline Average & 200.0 & 217.4 & 233.2 & 241.6 \\
\hline S2 & 188.8 & 229.0 & 190.4 & 185.5 \\
\hline $\mathrm{S} 4$ & 225.0 & 251.9 & 228.6 & 237.0 \\
\hline $\mathrm{S} 8$ & 195.8 & 215.3 & 212.2 & 213.4 \\
\hline S9 & 224.8 & 236.5 & 210.9 & 244.0 \\
\hline S1 & 191.5 & 219.6 & 168.2 & 206.0 \\
\hline S5 & 206.0 & 232.1 & 225.3 & 234.4 \\
\hline $\mathrm{S} 10$ & 180.8 & 189.0 & 186.8 & 191.8 \\
\hline $\mathrm{S} 13$ & 168.7 & 200.0 & 206.2 & 184.1 \\
\hline Average $\pm \mathrm{SE}$ & $197.7 \pm 7.1$ & $221.6 \pm 7.2$ & $202.8 \pm 7.6$ & $212.0 \pm 8.5$ \\
\hline $\mathrm{R} 2$ & 179.8 & 168.6 & 209.3 & 261.5 \\
\hline $\mathrm{R} 3$ & 124.6 & 158.1 & 133.6 & 148.8 \\
\hline $\mathrm{R} 6$ & 198.3 & 202.2 & 207.1 & 244.9 \\
\hline $\mathrm{R} 18$ & 185.7 & 221.6 & 222.5 & 254.4 \\
\hline $\mathrm{R} 17$ & 167.1 & 193.9 & 196.7 & 200.0 \\
\hline $\mathrm{R} 8$ & 242.6 & 217.0 & 197.1 & 247.9 \\
\hline $\mathrm{R} 12$ & 153.8 & 150.4 & 157.0 & 186.8 \\
\hline R7 & 178.4 & 166.3 & 177.3 & 212.8 \\
\hline Average $\pm \mathrm{SE}$ & $178.8 \pm 11.4$ & $184.8 \pm 9.2$ & $187.6 \pm 9.9$ & $219.6 \pm 13.2$ \\
\hline
\end{tabular}


more conservative approach is to compare cell sizes either between or within groups of animals, where all members of one group have received the same treatment. In such situations, the average size of each 100 cells measured in each laminar region of each animal serves as a single data point. For example, in an experimental group containing 5 animals, the overall mean for cells in lamina $\mathrm{A}$ is the average of five separate means, each of which represents the average of 100 cells. Likewise, the standard error of the mean (SE) is a measure of the variability between the means for the individual animals.

For the present analyses, we made within group comparisons only, using $t$ tests for dependent measures. While statistical comparisons between corresponding laminae in the two hemispheres can be used to demonstrate changes in average cell size, such comparisons do not, by themselves, indicate in which hemisphere such changes have occurred. There is, however, a consistent size relationship between cells in the different laminae of each geniculate. Using the cell size data provided by several authors (Guillery, 1973; Kalil, 1978; Hickey, 1980), we find that normal lamina $\mathrm{A}_{1}$ cells are, on average, 10.39 $\pm 0.7 \%$ (SE) larger than normal binocular segment lamina A cells in the same nucleus. Following monocular deprivation, lamina A cells contralateral to the deprived eye and lamina $A_{1}$ cells ipsilateral to the deprived eye are reduced in size. Thus, in most instances, monocular deprivation changes the cell size relationship in both hemispheres and the relative magnitude of the change in each hemisphere can indicate on which side of the brain the cell size changes have occurred.

\section{Results}

Normal cats receiving either 6-OHDA or NE. Two normal adult cats (S6 and S12) and 3 normal kittens (S7, T.JE3, and Silver I) (see Fig. 1) received either intraventricular injections of 6-OHDA (TJE3 and Silver I) or local perfusions of NE (S6, S7, and S12). In terms of their cortical cell physiology, these 5 cats appeared normal, with the only exception being a decrease in the proportion of cells dominated by the ipsilateral eye in the NEtreated animals (Kasamatsu et al., 1979; Kupperman and Kasamatsu, 1979). When geniculate cells were measured in these animals, the average size of the cells in the different laminar regions did not vary appreciably between hemispheres ( $p=0.32$ for lamina A cells; $p=0.49$ for lamina $\mathrm{A}_{1}$ cells).

Deprived but otherwise untreated kittens. Three kittens (TB, TC, and TD, not shown in Fig. 1) underwent 1 week of monocular deprivation beginning in the 6 th week of life. None of these kittens underwent any additional experimental treatments and none were studied electrophysiologically. The changes in geniculate cell size in these animals were consistent with those generally reported for deprived cats. Lamina A cells contralateral to the sutured eye were, on average, $14 \%$ smaller than cells in the ipsilateral (nondeprived) lamina $\mathrm{A}(p=0.01)$. Likewise, lamina $A_{1}$ cells ipsilateral to the sutured eye were, on average, $10 \%$ smaller than the contralateral (nondeprived) lamina $\mathrm{A}_{1}$ cells ( $p=0.05$; see Table I). In terms of the cell size relationships between laminae within each nucleus, in the left hemisphere of these kittens, the nondeprived lamina $A_{1}$ cells were, on average, $20.8 \%$ larger than the deprived lamina A cells; in the right hemisphere, on the other hand, the deprived lamina $A_{1}$ cells were, on average, $6.8 \%$ smaller than the nondeprived lamina A cells.

Deprived cats receiving $N E$. One 9-week-old kitten (S2), 3 13-week-old kittens (S4, S8, and S9), and 4 adult cats (S1, S5, S10, and S13) were monocularly deprived for either 1 week (S1, S4, and S8), 2 weeks (S5, S9, and $\mathrm{S} 10)$, or 3 weeks (S13) during which time they received continuous local perfusions of NE (see Fig. 1). Although even the youngest of these animals (S2) was well past the most sensitive part of the "critical period" (Hubel and Wiesel, 1970; also see "Discussion"), cortical cell recordings showed a decrease in binocularity in the experimental, NE-treated hemisphere after as little as 1 week of monocular deprivation. However, the resulting U-shaped ocular dominance distributions indicate that, even in the experimental hemisphere of these animals, the deprived eye maintains control over many cortical cells. Accordingly, no changes in cortical cell binocularity were found in the untreated, control hemisphere when the concentration of the NE perfused into the experimental hemisphere was kept low. The average sizes of the cells in the deprived and nondeprived laminae are shown in Figure 2. On average, geniculate cell size is not affected by monocular deprivation ( $p=0.20$ for lamina A cells; $p=0.07$ for lamina $A_{1}$ cells) in the NE-treated older kittens and adult cats (see Table I). Since these animals exhibited U-shaped ocular dominance distributions, indicating that the deprived eye still maintained control over many cortical cells, it is not surprising that geniculate cell size changes did not occur.

Deprived kittens receiving both 6-OHDA and NE. A total of 8 monocularly deprived kittens received intraventricular injections of 6-OHDA along with (R2, R3, $\mathrm{R} 6$, and R18) or immediately followed by (R7, R8, R12, and R17) local perfusions of NE into the left hemisphere (see Fig. 1). In addition, each of these cats (except animal

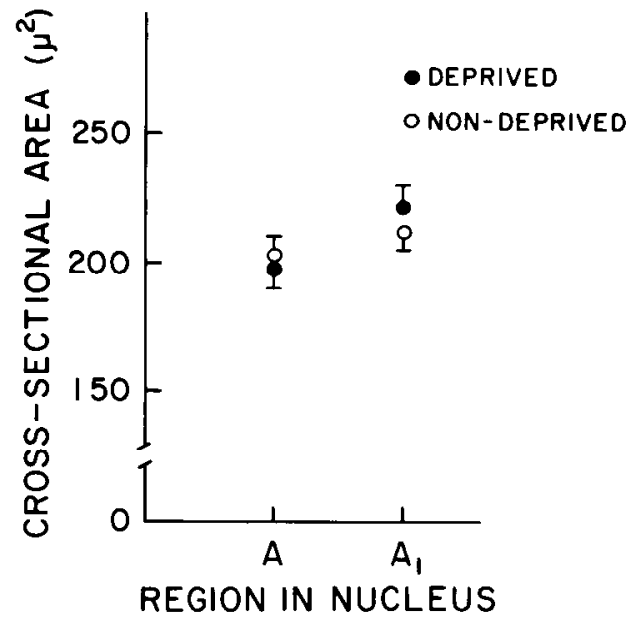

Figure 2. Average $( \pm \mathrm{SE})$ cross-sectional area for cells in the binocular segment of lamina $A$ and lamina $A_{1}$. The animals represented (S1, S2, S4, S5, S8, S9, S10, and S13) were monocularly deprived (right eye) for 1 to 3 weeks during which time they received continuous local perfusions of $\mathrm{NE}$ in the left hemisphere. 
$\mathrm{R} 2$ ) received a local perfusion of the vehicle solution in the right, control hemisphere. In general, these animals showed a loss of binocularity and dramatic shifts in ocular dominance away from the deprived eye for recordings made in the experimental, NE-treated hemisphere. Recordings made at similar points in the control hemisphere appeared normal when the concentrations of the NE in the experimental hemisphere were kept low. Figure 3 shows that cells in the deprived laminae of these cats were, on average, smaller than cells in the corresponding regions of the nondeprived laminae, although these differences reached significance only for lamina $A_{1}$ cells ( $p=0.18$ for lamina A cells; $p=0.006$ for lamina $\Lambda_{1}$ cells; see Table I and "Discussion"). Comparisons of the cell size relationships between laminae $A$ and $A_{1}$ in each hemisphere indicate that changes in this relationship occurred in both hemispheres. In the right hemisphere, deprived lamina $A_{1}$ cells were, on average, $1.5 \%$ smaller than nondeprived lamina A cells, whereas, nondeprived lamina $\mathrm{A}_{1}$ cells in the left hemisphere were $22.8 \%$ larger than the deprived lamina $A$ cells in the same nucleus. Relative to the A- $\mathrm{A}_{1}$ cell size relationship seen in normal animals, the relative sizes of the A laminae cells in each LGN of these animals suggest that the deprivation-induced changes in geniculate cell size were about equal in both hemispheres $(12.41 \%$ change in the left hemisphere and $11.89 \%$ change in the right hemisphere).

\section{Discussion}

Does either 6-OHDA or NE affect geniculate cell size in normal animals? The cross-sectional area measurements made in the 5 normally reared kittens and adult cats show that neither intraventricular injections of 6OHDA nor local perfusions of NE are accompanied by changes in geniculate cell size when comparisons are made between the two hemispheres.

Do intraventricular injections of 6-OHDA prevent deprivation-induced changes in geniculate cell size? All

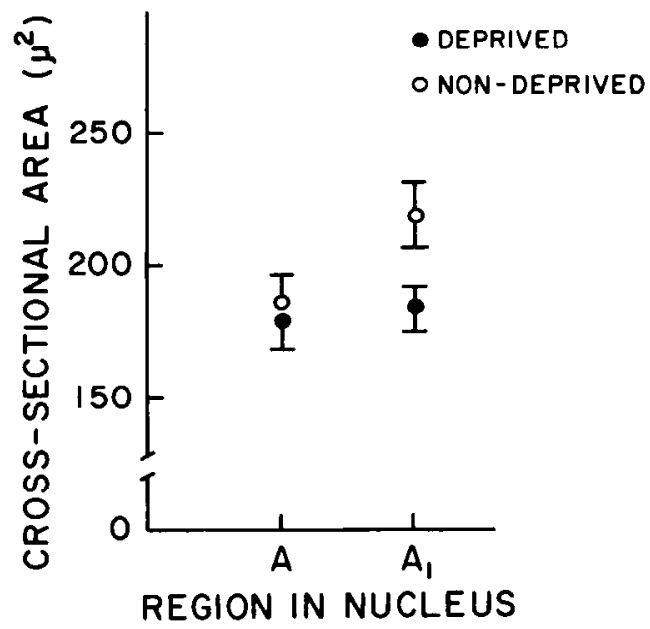

Figure 3. Average ( $\pm \mathrm{SE}$ ) cross-sectional area for cells in the binocular segment of lamina $A$ and lamina $A_{1}$. The animals represented ( $R 2, \mathrm{R} 3, \mathrm{R} 6, \mathrm{R} 7, \mathrm{R} 8, \mathrm{R} 12, \mathrm{R} 17$, and $\mathrm{R} 18)$ were monocularly deprived (right eye) for 1 week during which time they received intraventricular injections of 6-OHDA along with, or immediately followed by, local perfusions of NE in the left hemisphere. See the text and Figure 1 for additional details. deprived kittens receiving intraventricular injections of 6-OHDA also received local perfusions of $\mathrm{NE}$ in the left, experimental hemisphere. In general, the physiological experiments undertaken in these animals (Kasamatsu et al., 1979) showed a breakdown in binocularity and a dramatic shift in ocular dominance away from the deprived eye for recordings made in the NE-treated hemisphere but not, usually, for recordings made in the control hemisphere. However, when changes in geniculate cell size are considered, deprived cells are found to be significantly smaller than their nondeprived counterparts only in lamina $A_{1}$ ipsilateral to the deprived eye (i.e., in the control hemisphere) and not on the side of the brain exposed directly to the NE. These anatomical findings suggest that the protection from the effects of brief deprivation afforded cortical cells as a result of the depletion of catecholamine terminals by 6 -OHDA does not extend to geniculate cells.

Is the restoration of cortical plasticity brought about by NE also reflected in deprivation-induced changes in geniculate cell size? For the most part, the answer to this question must be no. In the electrophysiological experiments described by Kasamatsu et al. (1979), NE restored, in part, plasticity lost either as a result of age or as a result of prior, intraventricular injections of 6-OHDA. The partial restoration of plasticity in older kittens and adult cats is not accompanied by any significant changes in geniculate cell size. In younger kittens, the restoration of physiological plasticity in the experimental hemisphere is measured against a background condition (control hemisphere) brought about by the prior 6-OHDA treatment. Since we must assume, at least for the present, that 6-OHDA does not prevent deprivation-induced changes in geniculate cell size and since 1 week of monocular deprivation does result in significant changes in geniculate cell size, the question becomes whether NE enhances such changes. Our present findings do not provide any strong support for such an enhancement. Rather, the cell shrinkage in both the experimental and control hemispheres is well within the range of what might be expected based on our findings in the 3 monocularly deprived, but otherwise untreated, kittens (TB, TC, and TD).

Relationship between changes in geniculate cell size and changes in cortical physiology. In general, the deprivation-induced changes in geniculate cell size reported here do not parallel the changes in cortical cell physiology that took place in these same animals (Kasamatsu et al., 1979). For example, comparisons between the deprivation-induced anatomical and physiological changes occurring in monocularly deprived kittens treated with both 6-OHDA and NE (see Fig. 3) suggest inconsistencies. In these animals, significant changes in geniculate cell size did not occur in the left, NE-treated hemisphere even through varying degrees of physiological change were evident in the left visual cortex. In addition, changes in geniculate cell size did occur in the control hemisphere, even in the absence of any physiological changes in cortical cell binocularity or ocular dominance.

There are other examples of changes in cortical cell physiology either not being reflected in geniculate cell size at all (Kalil, 1980; LeVay et al., 1980; Geisert et al., 
1980) or only being reflected in geniculate cell size after a delay of several weeks (Spear and Hickey, 1979; however, see Dürsteller et al., 1976). There is evidence here and elsewhere (for example, see Hubel and Wiesel, 1970; Wan and Cragg, 1976; LeVay et al., 1980) to show that 1 week of lid suture can result in quite obvious anatomical changes in the visual system, if the deprivation is begun early. However, the time of onset of the lid suture is a critical factor since short periods of deprivation are not as effective when begun late in the "critical period" (for example, see Blakemore and Van Sluyters, 1974; LeVay et al., 1980). This fact most likely accounts for the lack of any statistically significant deprivation-induced geniculate cell size changes in the older deprived kittens and adult cats that received NE (see Fig. 2). Since each of our 3 monocularly deprived but otherwise untreated kittens (TB, TC, and TD) showed deprivation-induced changes in geniculate cell size following only 1 week of lid suture, it is difficult to argue that the duration of the lid suture alone was a limiting factor for all animals. In many of the animals, however, the duration of the deprivation may have interacted with the time of its onset in such a way as to limit, or abolish, deprivation-induced changes in geniculate cell size. In many of the animals studied here, the period of time during which short term monocular deprivation could induce changes in geniculate cell size may have either ended or have been nearing completion at the time the lid suturing took place. In the monkey, there is evidence to suggest that deprivationinduced changes in cortical physiology can occur even after this period of anatomical susceptibility has ended (LeVay et al., 1980). Norepinephrine appears to play a role in enhancing, or restoring, this cortical level plasticity that seems to outlive the "critical period" for deprivation-induced structural changes in the lateral geniculate nucleus.

Since the anatomical data presented here is, for the most part, limited to animals used in prior electrophysiological studies, it is possible that further studies would alter some of our conclusions. For example, changes in cortical physiology vary depending upon the concentration of the NE present. It is possible that animals receiving more concentrated $\mathrm{NE}$, animals receiving $\mathrm{NE}$ for longer periods of time, or animals receiving $\mathrm{NE}$ applied directly to the LGN might show changes in geniculate cell size that more closely parallel changes in cortical physiology.

\section{References}

Blakemore, C., and R. C. Van Sluyters (1974) Reversal of the physiological effects of monocular deprivation in kittens: Further evidence for a sensitive period. J. Physiol. (Lond.) 237: 195-216.
Dürsteller, M. R., L. J. Garey, and J. A. Movshon (1976) Reversal of the morphological effects of monocular deprivation in the kitten's lateral geniculate nucleus. J. Physiol. (Lond.) 261: 189-210.

Geisert, E. E., P. D. Spear, and A. Langsetmo (1980) Return of $\mathrm{Y}$-cells in the lateral geniculate nucleus of monocularly deprived cats. Soc. Neurosci. Abstr. 6: 789.

Guillery, R. W. (1973) The effects of lid suture upon the growth of the cells in the dorsal lateral geniculate nucleus of kittens. J. Comp. Neurol. 148: 417-422.

Hickey, T. L. (1980) Development of the dorsal lateral geniculate nucleus in normal and visually deprived cats. J. Comp. Neurol. 189: 467-481.

Hickey, T. L., P. D. Spear, and K. E. Kratz (1977) Quantitative studies of cell size in the cat's dorsal lateral geniculate nucleus following visual deprivation. J. Comp. Neurol. 172: 265-282.

Hubel, D. H., and T. N. Wiesel (1970) The period of susceptibility to the physiological effects of unilateral eye closure in kittens. J. Physiol. (Lond.) 206: 419-436.

Kalil, R. E. (1978) Development of the dorsal lateral geniculate nucleus in the cat. J. Comp. Neurol. 182: 265-292.

Kalil, R. E. (1980) A quantitative study of the effects of monocular deprivation on cell growth in the dorsal lateral geniculate nucleus of the cat. J. Comp. Neurol. 189: 483-524.

Kasamatsu, T., and J. D. Pettigrew (1976) Depletion of brain catecholamines: Failure of ocular dominance shift after monocular occlusion in kittens. Science 194: 206-209.

Kasamatsu, T., and J. D. Pettigrew (1979) Preservation of binocularity after monocular deprivation in the striate cortex of kittens treated with 6-hydroxydopamine. J. Comp. Neurol. 185: 139-162.

Kasamatsu, T., J. D. Pettigrew, and M. Ary (1979) Restoration of visual cortical plasticity by local microperfusion of norepinephrine. J. Comp. Neurol. 185: 163-182.

Kasamatsu, T., T. Itakura, and G. Jonsson (1981) Intracortical spread of exogenous catecholamines: Effective concentration for modifying cortical plasticity. J. Pharmacol. Exp. Ther. 217: 841-850.

Kupperman, B., and T. Kasamatsu (1979) Binocular interaction: Its enhancement by norepinephrine. Soc. Neurosci. Abstr. 5: 792 .

LeVay, S., T. N. Wiesel, and D. H. Hubel (1980) The development of ocular dominance columns in normal and visually deprived monkeys. J. Comp. Neurol. 191: 1-51.

Pettigrew, J. D., and T. Kasamatsu (1978) Local perfusion of noradrenaline maintains visual cortical plasticity. Nature 271: 761-763.

Sanderson, K. J. (1971) The projection of the visual field to the lateral geniculate and medial interlaminar nuclei of the cat. J. Comp. Neurol. 143: 101-118.

Spear, P. D., and T. L. Hickey (1979) Postcritical-period reversal of effects of monocular deprivation on dorsal lateral geniculate cell size in the cat. J. Comp. Neurol. 185: 317-328.

Tusa, R. J., L. A. Palmer, and A. C. Rosenquist (1978) The retinotopic organization of area 17 (striate cortex) in the cat. J. Comp. Neurol. 177: 213-236.

Wan, Y. K., and B. Cragg (1976) Cell growth in the lateral geniculate nucleus of kittens following the opening or closing of one eye. J. Comp. Neurol. 166: 365-372. 